\title{
Medicolegal Aspects of Obstructive Sleep Apnea
}

\author{
AS Pon Thelac ${ }^{1}$, Nileena N KakkattuMana ${ }^{2}$, Nagarajan Ramakrishnan ${ }^{3}$
}

\begin{abstract}
The prevalence of obstructive sleep apnea (OSA) has been steadily increasing in recent decades. Correspondingly, the legal implications of this chronic disease are also being recognized and addressed. The insurance coverage for diagnosis and management of OSA and the medicolegal implications of undiagnosed OSA is clearly defined in some western countries. Health insurance coverage in India is predominantly for hospitalization and chronic disorders, such as OSA, are often not covered. In this review, we describe and compare the current status of medical and legal aspects in different countries, including issues related to health insurance, driving license, disability status, professional indemnity, and perioperative liabilities. We call to attention the need for more robust legislation in India relating to sleep disorders.
\end{abstract}

Keywords: Disability, Health insurance, Legal implications, Liability, Litigations, Medicolegal, Obstructive sleep apnea.

Indian Journal of Sleep Medicine (2019): 10.5005/jp-journals-10069-0039

\section{INTRODUCTION}

Sleep-related breathing disorders are being increasingly recognized in recent decades. Obstructive sleep apnea (OSA) is the most common sleep-disordered breathing disorder, which is characterized by recurrent episodes of upper airway obstruction during sleep. The prevalence of OSA, according to a review article by Franklin and Lindberg ${ }^{1}$ is $22 \%$ (range, $9-37 \%$ ) in men and $17 \%$ (range, 4-50\%) in women. In India, the prevalence of OSA was observed by Udwadia et al. ${ }^{2}$ to be approximately $19.5 \%$. Sharma et al. ${ }^{3}$ had shown that the prevalence of OSA was about $19.7 \%$ in men and $7.4 \%$ in women. However, the awareness pertaining to OSA is still abysmal, and the disease is largely under-recognized and under-reported in our country. Hence, the above statistical data may represent the tip of the iceberg.

Due to recurrent episodes of airway obstruction during sleep, OSA patients suffer from repeated hypoxia and arousal. The major daytime manifestations consist excessive daytime sleepiness, cognitive decline, and mood disturbances. Patients with OSA who undergo surgery tend to have prolonged hospital stay and increased risk of complications during the perioperative period. Unrecognized OSA has therefore been one of the reasons for medicolegal litigation when patients experience unexpected perioperative complications. Litigation relating to drowsy driving, insurance claims in patients with OSA have on occasions-held employers liable. ${ }^{4}$

Chronic diseases, such as coronary disease, cerebrovascular disease (stroke), and chronic kidney disease have been recognized by the Indian health ministry and suitable insurance policies are proposed. Unlike in Western Healthcare, the legal framework for OSA is not clearly defined in India. This has led to some controversial verdicts. In this article, we aim to point out the significance of diagnosis and management of this sleep disorder and emphasize the need for appropriate medicolegal framework and support for these patients.

\section{Literary Review}

We reviewed the published data on the legal implications of OSA. Literature review was conducted by searching Google Scholar and PubMed databases to find relevant published data till June 2019,

\footnotetext{
${ }^{1-3}$ Nithra Institute of Sleep Sciences, Anna Nagar, Chennai, Tamil Nadu, India
}

Corresponding Author: Nagarajan Ramakrishnan, Nithra Institute of Sleep Sciences, Anna Nagar, Chennai, Tamil Nadu, India, Phone: +91 44 4350 2252, e-mail: icudoctor@gmail.com

How to cite this article: Pon Thelac AS, KakkattuMana NN, Ramakrishnan N. Medicolegal Aspects of Obstructive Sleep Apnea. Indian J Sleep Med 2019;14(3):51-53.

Source of support: Nil

Conflict of interest: None

using the following combined search terms: "Obstructive sleep apnea" or "OSA," "medicolegal consequences," "legal implications," "litigations," "liability," "insurance fraud," and "disability status." We have reviewed the reference list of retrieved articles to expand the search.

Based on the available articles, we have focused on (1) driving license regulations, (2) employer's vicarious liability, (3) insurance policies, (4) surgery-related liabilities, and (5) sleep-related violence/ civil cases.

\section{Regulations in Issuing Driving License}

Sleep-related breathing disorders are one of the major causes of daytime sleepiness in a sober person. Recent research has concluded that about $9.5 \%$ of car crashes are due to drowsy driving. Although sleep apnea was recognized in the latter half of the 21st century, legal battles pertaining to sleepy driving were filed as early as 1925. A multitude of similar cases has emerged since then leading to stringent laws against drowsy driving. In the USA, Maggie's law and Arkansas Act 1296 deems drowsy driving as a criminal liability and is regarded as equivalent to vehicular homicide. ${ }^{4}$ Some states in the USA (such as California, New Jersey) have made it mandatory for the applicants to notify the licensing authorities regarding their OSA status. On a similar note, the European Union Directive on Driving Licenses was revised in 2014 where the applicants are to undergo a formal examination if they are suspected to be suffering from OSA. Once the diagnosis is established the licenses are issued or renewed only after substantiation of treatment controlling OSA symptoms. ${ }^{5}$

(c) The Author(s). 2019 Open Access This article is distributed under the terms of the Creative Commons Attribution 4.0 International License (https://creativecommons. org/licenses/by-nc/4.0/), which permits unrestricted use, distribution, and non-commercial reproduction in any medium, provided you give appropriate credit to the original author(s) and the source, provide a link to the Creative Commons license, and indicate if changes were made. The Creative Commons Public Domain Dedication waiver (http://creativecommons.org/publicdomain/zero/1.0/) applies to the data made available in this article, unless otherwise stated. 
In the UK, failure to notify daytime sleepiness, irrespective of the severity of OSA can entitle a fine of up to $£ 1,000 .^{6}$ Also, in some countries, presence of uncontrolled OSA impacts car insurance, and the collision coverage (accidents involving hitting stationary objects) will be significantly reduced. ${ }^{7}$

An exhaustive report submitted by the road transport and highways ministry of India reveals that driver's error (77.5\%) is one of the key causes of road traffic accidents (RTA) and nearly $25 \%$ of lethal and severe accidents are due to reduced alertness level of the drivers. ${ }^{8}$ There are not many publications elaborating the prevalence of drowsiness in Indian drivers due to OSA. Dubey et al. explored the prevalence of OSA in male applicants for a driver's license in India. The study revealed the prevalence of OSA to be about $6.7 \%$ in young ( $<35$ years), $34 \%$ in the middle age (35-45 years), and around $74 \%$ in men over 45 years of age. The Indian Initiative on Obstructive Sleep Apnea Guidelines (2014) proposed that individuals with a history of EDS, habitual snoring, obesity, hypertension, RTA, and others with high risk should undergo a complete clinical assessment, but no legal framework is in place till date. Hence, it is high time that appropriate legislation be passed for screening the presence of OSA in driving license applicants. ${ }^{9}$

\section{Health Insurance Claims}

The scenario involving health insurance claims related to OSA is entirely different in India compared with Western countries. In the USA, most people have third party private insurance (often provided as a benefit by employers) or government-supported medicare/medicaid and are eligible to get reimbursed for polysomnographies and continuous positive airway pressure (CPAP) services. It was observed that medicare costs increased by 39\% from $\$ 407$ million in 2005 to $\$ 565$ million in 2011. Interestingly, it was noted that $\$ 17$ million was paid for polysomnography services that did not meet medicare requirements. ${ }^{10}$ This observation led to stringent policies for licensing sleep labs and several of them had to shut down. Also, it was emphasized that sleep testing can be ordered and performed only by board-certified doctors and technicians in sleep medicine. Stark's law, Federal false claims act, and anti-kickback statuettes were legalized to curb unnecessary testing and insurance claims. While Stark's law prevents physicians from referring a patient (covered by insurance) to a lab where the physician holds a direct financial relationship, anti-kickback laws prohibit receiving rewards for referrals.

In India, less than $20 \%$ of the population is covered under health insurance, and in urban settlements around $82 \%$ of the population remain uninsured. ${ }^{11}$ The recently introduced Pradhan Mantri Jan Arogya Yojana may change this landscape significantly. While false claims and insurance frauds were the predominant issues in Western countries, the issue in India is the lack of coverage for diagnosis and treatment of OSA. Two court proceedings in India are worth mentioning: (1) NK Jain vs United India Insurance ${ }^{12}$ and (2) Rajendra vs New India Insurance. ${ }^{13}$ Both the patients filed claim to reimburse the cost of CPAP, which was prescribed when they were diagnosed with OSA. The same mediclaim insurance policy was applied, but the rulings were different in both cases. This discrepancy is probably explained by the lack of mention of OSA among listed health problems for coverage despite reported prevalence as high as $23.65 \%$ adults with comorbidities such as uncontrolled diabetes. ${ }^{14}$

\section{Disability Status}

Sleepy workers find it difficult to stay focused, especially if their work is passive in nature. In some countries, sleep apnea has been deemed as a disability providing the platform for appropriate privileges and in these countries firing an employee based on his disability is treated as an offense. Two litigations deserve special mention: Jackson vs Bois Carcade Corporation and Brohm vs JH properties. Jackson was a wood yard worker operating heavy machinery and was fired for sleeping on the job. He claimed using the disability act and filed a case for wrongful termination as he had been ailing from sleep apnea. Brohm was an anesthesiologist who was reported to be sleepy during surgery and was terminated for the same. However, his legal claim was dismissed as he was not compelled to perform the anesthesia, and he chose to proceed with his duties in spite of his drowsiness and the knowledge regarding the possible negative consequences. ${ }^{10}$

The disability status of sleep apnea in India has been gaining attention. The Rights of Disability Act 2016, ${ }^{15}$ points to criteria of "Disability," which states that "person with disability means a person with long-term physical, mental, intellectual, or sensory impairment which, in interaction with barriers, hinders his full and effective participation in society equally with others." Although no legal claims have been filed regarding the disability status of OSA in India, we can expect controversial disputes unless the disability status of OSA is acknowledged and appropriate guidelines are in place. Neurocognitive dysfunction in OSA has been shown to respond to CPAP and disability claims may be difficult to justify unless they persist despite appropriate treatment.

It should also be pointed out that employers shall be held responsible for the negligent acts of the employees attributed to OSA during work hours. It is, therefore, the duty of the employers to screen their workers before recruitment and also monitor periodically. In the Dunlap vs WL Trucking Co. case, the company was held vicariously liable for one of its drivers as he was involved in an RTA because of drowsiness (owing to OSA). Legal framework insisting on screening and treatment of common causes of excessive sleepiness, such as sleep deprivation and OSA, should be developed for truck drivers, railway operators, pilots, and other safety-sensitive occupations involving many lives.

\section{Medical Liabilities}

It has been observed that OSA-related malpractice claims are more with regard to perioperative complications rather than claims relating to failure to diagnose a patient. Nonetheless, the statistical data among published articles are highly variable, and the reliability of these statistics is poor due to numerous off-court settlements. It is worrisome to note that the average plaintiff settlement amount to about $\$ 2$ million and many law firms in the USA have started advertising about their specialization in dealing with OSA-related malpractices. ${ }^{16}$ Failure to recognize the complications of OSA during the perioperative period, such as airway collapse need for re-intubation or tracheostomy have led to an unfavorable response from the jury. ${ }^{17}$ Also, both the anesthesiologist and the treating surgeon shall be "sharing the responsibility" for OSA-related complications. ${ }^{18}$ With the number of false allegations on the rise, doctors need to be comprehensive in preoperative screening, and management of their patients.

\section{Sleep-related Violence and Civil Cases}

Media reports two different spectra of snoring-related incidents. At one end, they point out the "triviality" of snoring being an absurd reason for divorce, while at the other end they report incidents of 
snoring provoking a person to make an attempt to kill the partner. It has been stated that snoring is the third leading cause of divorce in the USA (next only to infidelity and financial issues). ${ }^{19}$

Nofzinger et al. ${ }^{20}$ have reported a case where a 37 -year-old laborer shot his wife. He claimed total amnesia about the event. Although he had a history of somniloquy and sleepwalking in childhood, there were no such incidents in his adulthood. He had a diagnosis of OSA and abusive episodes in his relationship. Eventually, he was declared guilty. However, this makes us question if the above incident could be a confusional state/parasomnia triggered by OSA or neuropsychological effects due to chronic hypoxemia. Parasomnias are more often associated with sleeprelated violence than OSA and appropriate evaluation and treatment is essential.

\section{Challenges}

Medicolegal aspects pertaining to OSA are a reality but there are challenges in creating and enforcing a legal framework. ${ }^{21}$

- Lack of objective methods to document drowsy driving and a clear dose-response relationship between sleepiness and risk of RTA.

- Lack of uniformity in physician reporting to regulatory authorities because of which impaired patients may continue to drive.

- Lack of guidelines in pre-employment screening in determining disability-related to excessive sleepiness and impaired work performance.

- Consciousness is not an all or none state but a spectrum leading to challenges in ascribing culpability in sleep-related violence that could happen due to hypoxemia in patients with OSA or due to parasomnias.

- While preoperative screening for OSA will certainly reduce risks of postoperative complications, should it be the responsibility of surgeons and anesthetists only or primary care physician and other referral consultants as well? In countries with large population and resource limitations, is it practical to screen all patients?

\section{Conclusion}

It has long been established that OSA is a disease with various social and medicolegal implications. However, in the Indian scenario, the multitude of legal repercussions due to this disorder has just begun to gain attention. Clinicians and employers should be aware of these legal implications and embark upon appropriate screening protocols and management. Also, persons suffering from OSA should be made aware, not only of their legal culpabilities but also their rights to lead a better life to cope well with their disease.

\section{References}

1. Franklin KA, Lindberg E. Obstructive sleep apnea is a common disorder in the population-a review on the epidemiology of sleep apnea. J Thorac Dis 2015;7(8):1311-1322. DOI: 10.3978/j.issn.20721439.2015.06.11.

2. Udwadia ZF, Doshi AV, Lonkar SG, et al. Prevalence of sleep-disordered breathing and sleep apnea in middle-aged urban Indian men. Am J
Respir Crit Care Med 2004;169(2):168-173. DOI: 10.1164/rccm.200302$2650 C$.

3. Sharma SK, Kumpawat S, Banga A, et al. Prevalence and risk factors of obstructive sleep apnea syndrome in a population of Delhi, India. Chest 2006;130(1):149-156. DOI: 10.1378/chest.130.1.149.

4. Venkateshiah SB, Hoque R, Collop N. Legal aspects of sleep medicine in the 21st century. Chest 2018;154(3):691-698. DOI: 10.1016/ j.chest.2018.04.033.

5. Ghosh D, Mackay TW, Riha RL. European Union directive 2014/85/EU on driver licensing in obstructive sleep apnoea: early experiences with its application in the UK. Breathe (Sheffield, England) 2016;12(3):e59-e63. Available from: http://www.ncbi.nlm.nih.gov/ pubmed/28194236.

6. The Sleep Apnoea Trust Association. Detailed DVLA Guidance for UK Drivers with Sleep Apnoea-Updated 23rd Jan 2019-Sleep Apnoea Trust. Updated 23rd Jan. 2019 [cited 2019 Oct 11]. Available from: http://www.sleep-apnoea-trust.org/driving-and-sleep-apnoea/ detailed-guidance-to-uk-drivers-with-sleep-apnoea/.

7. Does sleep apnea affect car insurance? [cited 2019 Oct 11]. Available from: https://www.autoinsurance.org/does-having-sleep-apneaaffect-your-car-insurance/.

8. Gopalakrishnan S. A public health perspective of road traffic accidents. J Fam Med Prim Care 2012;1(2):144. DOI: 10.4103/2249-4863.104987. Available from: http://www.ncbi.nlm.nih.gov/pubmed/24479025.

9. Dubey A, Bajaj DK, Mishra A, et al. Obstructive sleep apnea risk for driving license applicants in india-a community based study. Int J Occup Med Env Health 2018;31(1):25-36.

10. Tan SY. Medicolegal aspects of sleep apnea CHEST Physician. 2015 [cited 2019 Oct 11]. Available from: https://www.mdedge.com/ chestphysician/article/102942/sleep-medicine/medicolegal-aspectssleep-apnea.

11. Singh A. Current Situation of Health Care Coverage in India. ISPOR, News Across Asia. 2016;5(Number 1 April-July). Available from: https:// www.ispor.org/consortiums/asia/NewsAcrossAsia_Spring2016.pdf.

12. Kumar Jain Narender, vs United India Insu. Co. Ltd. \&amp; Ors. on 12 December, 2013. [cited 2019 Oct 11]. Available from: https:// indiankanoon.org/doc/184463617/.

13. Rajendra Kapoor vs New India Assurance Co. Ltd. \&amp; Anr. on 12 May, 2016. [cited 2019 Oct 11]. Available from: https://indiankanoon. org/doc/51932122/.

14. Viswanathan V, Ramalingam IP, Ramakrishnan N. High prevalence of obstructive sleep apnea among people with type 2 diabetes mellitus in a tertiary care center. J Assoc Physicians India 2017;65(11):38-42.

15. The Rights of Persons with Disabilities Act, 2016, Gazette of India (Extra-Ordinary). 2016 [cited 2019 Oct 11]. Available from: http:// disabilityaffairs.gov.in/upload/uploadfiles/files/RPWD ACT 2016.pdf.

16. Failure to Diagnose Sleep Apnea - Miller \& Wagner. [cited 2019 Oct 11]. Available from: https://www.miller-wagner.com/malpractice/ diagnosis-errors/failure-to-diagnose-and-treat-sleep-apnea/.

17. Tolisano AM, Bager JM. Sleep surgery and medical malpractice. Laryngoscope 2014;124(6):E250-E254. DOI: 10.1002/lary.24559.

18. Fouladpour N, Jesudoss R, Bolden N, et al. Perioperative complications in obstructive sleep apnea patients undergoing surgery. Anesth Analg 2016;122(1):145-151. DOI: 10.1213/ANE.0000000000000841.

19. How snoring could harm your marriage or relationship. [cited 2019 Oct 11]; available from: https://www.ibtimes.co.in/how-snoringcould-harm-your-marriage-relationship-764099.

20. Nofzinger EA, Wettstein RM. Homicidal behavior and sleep apnea: a case report and medicolegal discussion. Sleep. 1995;18(9):776-782. DOI: $10.1093 /$ sleep/18.9.776.

21. Summaries of Current Drowsy Driving Laws. [cited 2019 Oct 11]. Available from: http://www.ncsl.org/research/transportation/ summaries-of-current-drowsy-driving-laws.aspx. 